\title{
EFFECT OF ALVEOLAR RECRUITMENT ON OXYGENATION AND CARBON DIOXIDE ELIMINATION DURING LAPAROSCOPIC BARIATRIC SURGERY AND COMPARISON WITH PRESSURE CONTROLLED AND VOLUME CONTROLLED VENTILATION
}

\author{
Gnanasekaran Srinivasan ${ }^{1}$, Renu Sinha², Rajeswari Subramaniam ${ }^{3}$, Chandralekha $^{4}$, Vimi Rewari ${ }^{5}$
}

${ }^{1}$ Assistant Professor, Department of Anaesthesiology \& Intensive Care, Pondicherry Institute of Medical Sciences, Puducherry. ${ }^{2}$ Additional Professor of Anaesthesiology, Dr. Rajendra Prasad Institute of Ophthalmic Sciences, All India Institute of Medical Sciences, New Delhi.

3 Professor, Department of Anaesthesiology\& Intensive Care, All India Institute of Medical Sciences, New Delhi.

${ }^{4}$ Former Professor, Department of Anaesthesiology \& Intensive Care, All India Institute of Medical Sciences, New Delhi.

5Professor, Department of Anaesthesiology \& Intensive Care, All India Institute of Medical Sciences, New Delhi.

ABSTRACT

\section{BACKGROUND}

Arterial oxygenation is inversely proportional to body mass index (BMI) in morbidly obese individuals. Alveolar recruitment maneuver consists of sustained insufflations, mainly with the use of positive end expiratory pressure (PEEP). We investigated the effects of alveolar recruitment on arterial oxygenation and carbon dioxide $\left(\mathrm{CO}_{2}\right)$ elimination and compared the same with volumecontrolled and pressure-controlled ventilation during laparoscopic sleeve gastrectomy in morbidly obese patients.

\section{MATERIALS AND METHODS}

In this prospective randomized study, thirty morbidly obese patients with BMI $>35 \mathrm{~kg} / \mathrm{m}^{2}$, American Society of Anesthesiologists (ASA) grade I and II between 18 and 60 years scheduled for laparoscopic sleeve gastrectomy under general anesthesia were included. They were randomly allocated into three groups of ten each using sealed envelope method. Group P received pressure controlled ventilation; group $\mathrm{V}$ received volume controlled ventilation. In group $\mathrm{R}$, alveolar recruitment maneuver was performed at 10 minutes after creation of pneumoperitoneum, by increasing the PEEP in a stepwise manner- initially to $10 \mathrm{~cm} \mathrm{H}_{2} \mathrm{O}$ for 3 breaths, then to $15 \mathrm{~cm} \mathrm{H}_{2} \mathrm{O}$ for 3 breaths and finally to $20 \mathrm{~cm} \mathrm{H}_{2} \mathrm{O}$ for 10 breaths and then PEEP was maintained at $12 \mathrm{~cm} \mathrm{H}_{2} \mathrm{O}$.

\section{RESULTS}

In the recruitment group, $\mathrm{PaO}_{2}$ at five minutes after recruitment was significantly higher than $\mathrm{PaO}_{2}$ at 5 minutes after intubation $(\mathrm{P}<0.005)$. However, there was no significant difference in the mean $\mathrm{PaO}_{2}$ and $\mathrm{PaCO}_{2}$ on comparing the three groups.

\section{CONCLUSION}

Our study showed that alveolar recruitment maneuver effectively improves oxygenation and this beneficial effect is transient. There was no significant difference in $\mathrm{PaO}_{2}$ and $\mathrm{PaCO}_{2}$ when recruitment maneuver was compared with both volume controlled and pressure controlled ventilation. Both volume control and pressure control ventilation can be utilized during laparoscopic bariatric surgery. Alveolar recruitment can be considered whenever an improvement in oxygenation is sought.

\section{KEYWORDS}

Morbid Obesity, Oxygenation, Alveolar Recruitment, PEEP.

HOW TO CITE THIS ARTICLE: Srinivasan G, Sinha R, Subramaniam R, et al. Effect of alveolar recruitment on oxygenation and carbon dioxide elimination during laparoscopic bariatric surgery and comparison with pressure controlled and volume controlle $d$ ventilation. J. Evolution Med. Dent. Sci. 2017;6(2):84-88, DOI: 10.14260/Jemds/2017/21

\section{BACKGROUND}

Morbid obesity results in several pathophysiologic changes of the respiratory system mechanics that promote the development of intraoperative atelectasis and exaggerate the impairment of gas exchange. Obesity is considered as independent risk factor for respiratory complications. It has been reported that arterial oxygenation is inversely related to body mass index (BMI). ${ }^{1}$

Financial or Other, Competing Interest: None.

Submission 28-11-2016, Peer Review 22-12-2016,

Acceptance 29-12-2016, Published 05-01-2017.

Corresponding Author:

Dr. Gnanasekaran Srinivasan,

Assistant Professor,

Department of Anesthesiology \& Intensive Care,

Pondicherry Institute of Medical Sciences,

Ganapathichettikulam, Village No. 20

Kalapet, Puducherry-605014.

E-mail:gnansdr@gmail.com

DOI: $10.14260 /$ jemds $/ 2017 / 21$
Maintenance of adequate ventilation and oxygenation is often a major problem in obese patients during general anaesthesia. The incidence of atelectasis is high in obese patients during general anaesthesia and immediate postoperative period compared to non-obese individuals. ${ }^{2}$

Different ventilatory strategies have been described for obese patients to expand the collapsed alveoli. Large tidal volume $\left(\mathrm{V}_{\mathrm{T}}\right)$ up to $20 \mathrm{ml} / \mathrm{kg}$ does not improve $\mathrm{PaO}_{2}$ in morbidly obese and may promote lung injury. ${ }^{3}$

Pressure controlled ventilation (PCV) uses a decelerating flow which produces high initial flow rate resulting in more rapid inflation of alveoli. The homogeneous distribution of ventilation produced by volume controlled ventilation (VCV) leads to improvement in ventilation perfusion matching. ${ }^{4}$

A number of studies suggested that alveolar recruitment is beneficial in opening atelectatic lung areas present during anesthesia and to improve arterial oxygenation. Alveolar recruitment maneuver consists of sustained insufflations, mainly with the use of positive end-expiratory pressure (PEEP). ${ }^{2}$ The application of high inspiratory pressure causes expansion of collapsed alveoli and increases the $\mathrm{PaO}_{2}$. 
Though there are various types of recruitment, irrespective of the mechanism, alveolar recruitment was found to improve oxygenation, ventilatory mechanics and the repair of damage to the lung epithelium. ${ }^{5}$

In our study, we evaluated the effect of alveolar recruitment on oxygenation and $\mathrm{CO}_{2}$ elimination during laparoscopic sleeve gastrectomy in morbidly obese patients. We also compared alveolar recruitment with the conventional pressure controlled ventilation and volume controlled ventilation in terms of arterial oxygenation and $\mathrm{CO}_{2}$ elimination.

\section{MATERIALS AND METHODS}

This study was a prospective, randomized, single centre study conducted in the Department of Anaesthesiology and Intensive care at All India Institute of Medical Sciences, New Delhi from August 2009 to February 2011. After institutional ethics committee approval and consent, 30 patients with BMI $>35 \mathrm{~kg} / \mathrm{m}^{2}$ between 18 and 60 years of both sexes scheduled for laparoscopic bariatric surgery were included in the study. Patients having major obstructive or restrictive respiratory disorder with a baseline $\mathrm{PaCO}_{2}>60 \mathrm{~mm} \mathrm{Hg}$ were excluded from the study. The patients were randomly assigned to one of the three groups, randomization done by using a sealed envelope method. Each group consisted of ten patients. Group $\mathrm{V}$ received VCV, group P received PCV and group R received alveolar recruitment.

Anaesthetic management was standardized as follows. After the patients were transferred to the operating room, standard monitors (ECG, non-invasive blood pressure and pulse oximetry) were attached. After preoxygenation, anaesthesia was induced with $2 \mathrm{mg} / \mathrm{kg}$ ideal body weight (IBW) of Propofol, supplemented by Fentanyl $2 \mu \mathrm{g} / \mathrm{kg}$ of lean body weight. Tracheal intubation was performed with appropriate sized endotracheal tube facilitated by $1.5 \mathrm{mg} / \mathrm{kg}$ total body weight of Succinylcholine. After intubation, radial artery was cannulated for invasive BP monitoring and intermittent arterial blood gas analysis.

In group $\mathrm{V}$, the ventilatory settings were made as follows; tidal volume $\left(\mathrm{V}_{\mathrm{T}}\right)$ of $8 \mathrm{ml} / \mathrm{kg} \mathrm{IBW}$, respiratory rate $(\mathrm{RR})$ of 12 breaths/min, inspiratory; expiratory ratio (I: E) of $1: 2$, positive end expiratory pressure (PEEP) of $5 \mathrm{~cm} \mathrm{H} \mathrm{H}_{2} \mathrm{O}$. End tidal $\mathrm{CO}_{2}$ (EtCO2) was adjusted to $40-48 \mathrm{~mm} \mathrm{Hg}$ by increasing the RR by 2 breaths/min (every 5 min till 18 breaths/min) and then $\mathrm{V}_{\mathrm{T}}$ was increased by $1 \mathrm{ml} / \mathrm{kg}$ till $12 \mathrm{ml} / \mathrm{kg}$ or peak airway pressure $\left(\mathrm{P}_{\text {peak }}\right)$ of $40 \mathrm{~cm} \mathrm{H}_{2} \mathrm{O}$. If the target $\mathrm{EtCO}_{2}$ was not achieved, then RR was increased to $25 / \mathrm{min}$ with a maximum peak airway pressure ( $\left(P_{\text {peak}}\right)$ of $40 \mathrm{~cm} \mathrm{H}_{2} \mathrm{O}$.

In group $\mathrm{P}$, patient's lungs were ventilated with a peak inspiratory pressure to deliver a VT of $8 \mathrm{ml} / \mathrm{kg} \mathrm{IBW,} \mathrm{RR} \mathrm{of} 12$ breaths/min, I:E ratio of 1:2, PEEP of $5 \mathrm{~cm} \mathrm{H}_{2} \mathrm{O}$. A target $\mathrm{EtCO}_{2}$ of $40-48 \mathrm{~mm} \mathrm{Hg}$ was maintained and if not achieved, then respiratory rate was increased by 2 breaths/min (every $5 \mathrm{~min}$, till 18 breaths/min). If target $\mathrm{EtCO}_{2}$ was still not achieved, then $\mathrm{P}_{\text {peak }}$ was increased by $2 \mathrm{~cm} \mathrm{H}_{2} \mathrm{O}$ increments till a maximum of $40 \mathrm{~cm} \mathrm{H}_{2} \mathrm{O}$. If the target $\mathrm{EtCO}_{2}$ was still not achieved, then RR was increased by 2 breaths/min to a maximum of 25 breaths/min.

In group $\mathrm{R}$, the ventilatory settings were made as follows; $\mathrm{V}_{\mathrm{T}}$ of $8 \mathrm{ml} / \mathrm{kg}$ IBW, RR of 12 breaths/min, I: E of 1:2, PEEP of $5 \mathrm{~cm} \mathrm{H}_{2} \mathrm{O}$. $\mathrm{EtCO}_{2}$ was maintained at $40-48 \mathrm{~mm} \mathrm{Hg}$ by increasing the RR by 2 breaths/min (every $5 \mathrm{~min}$ till 18 breaths/min) and then $\mathrm{V}_{\mathrm{T}}$ was increased by $1 \mathrm{ml} / \mathrm{kg}$ till 12 $\mathrm{ml} / \mathrm{kg}$ or peak airway pressure $\left(\mathrm{P}_{\text {peak }}\right)$ of $40 \mathrm{~cm} \mathrm{H} \mathrm{H}_{2} \mathrm{O}$. Lung recruitment manoeuvre was performed at 10 minutes after creation of pneumoperitoneum, by increasing the PEEP in a stepwise manner - initially to $10 \mathrm{~cm} \mathrm{H}_{2} \mathrm{O}$ for 3 breaths, then to $15 \mathrm{~cm} \mathrm{H}_{2} \mathrm{O}$ for 3 breaths and finally to $20 \mathrm{~cm} \mathrm{H}_{2} \mathrm{O}$ for 10 breaths and then PEEP was maintained at $12 \mathrm{~cm} \mathrm{H}_{2} \mathrm{O}$. If at any point during the recruitment manoeuvre $\mathrm{P}_{\text {peak }}$ exceeded $40 \mathrm{~cm} \mathrm{H}_{2} \mathrm{O}$, the next level of PEEP was discontinued.

Anaesthesia was maintained with a mixture of oxygen and air $\left(\mathrm{FiO}_{2}-0.5\right)$ and isoflurane. Neuromuscular blockade was maintained with Atracurium boluses. All patients were stabilized in the reverse Trendelenburg position. The intraabdominal pressure was maintained between 14-17 mm of Hg. Intra operative analgesia was supplemented with Paracetamol 1 gm intravenously and boluses of Fentanyl.

Parameters such as oxygen saturation $\left(\mathrm{SpO}_{2}\right), \mathrm{EtCO}_{2}$ and arterial blood gases (ABG) were measured. Baseline measurement was recorded at $5 \mathrm{~min}$ after intubation, second measurement at $5 \mathrm{~min}$ after creating pneumoperitoneum, and then every 15 minutes till the release of pneumoperitoneum. Postoperatively $\mathrm{O}_{2}$ requirement in hours, $\mathrm{SpO}_{2}$ and $\mathrm{ABG}$ were recorded.

\section{Statistical Analysis}

Statistical analysis was carried out using SPSS software. Data were presented as mean \pm standard deviation (SD). The demographic parameters, $\mathrm{SpO}_{2}, \mathrm{EtCO}_{2}$ and $\mathrm{ABG}$ were analysed using one way ANOVA test. $\mathrm{P}<0.05$ was considered significant and $\mathrm{P}>0.05$ not significant.

\section{RESULTS}

The demographic parameters such as age, sex, actual weight, ideal weight, height, BMI and comorbidities of the patients did not show any significant difference among the groups.

The room air arterial blood gas analyses $\left(\mathrm{pH}, \mathrm{PaO}_{2}, \mathrm{PaCO}_{2}\right)$ were comparable in all the 3 groups.

There is no statistical significance in the intraoperative $\mathrm{SpO}_{2}$ and $\mathrm{EtCO}_{2}$ values among the three groups. The intraoperative mean $\mathrm{PaO}_{2}$ and $\mathrm{PaCO}_{2}$ values are shown in tables 1 and 2 respectively and represented graphically in figures 1 and 2 respectively. There is no statistical significance in the ABG values among the three groups.

\begin{tabular}{|c|c|c|c|c|}
\hline $\begin{array}{c}\text { Time } \\
\text { (Minutes) }\end{array}$ & $\begin{array}{c}\text { Group V } \\
\text { Mean }( \pm \mathrm{SD})\end{array}$ & $\begin{array}{c}\text { Group P } \\
\text { Mean }( \pm S D)\end{array}$ & $\begin{array}{c}\text { Group R } \\
\text { Mean }( \pm \text { SD) }\end{array}$ & p Value \\
\hline Baseline & $\begin{array}{c}159.7 \\
( \pm 95.63)\end{array}$ & $\begin{array}{c}132.4 \\
( \pm 58.82)\end{array}$ & $\begin{array}{c}115.8 \\
( \pm 20.2)\end{array}$ & 0.337 \\
\hline $5 \mathrm{~min}$ & $\begin{array}{c}134.4 \\
( \pm 41.47)\end{array}$ & $\begin{array}{c}130.4 \\
( \pm 39.95)\end{array}$ & $\begin{array}{c}116.7 \\
( \pm 19.83)\end{array}$ & 0.507 \\
\hline $15 \mathrm{~min}$ & $\begin{array}{c}123.8 \\
( \pm 25.62)\end{array}$ & $\begin{array}{c}128.1 \\
( \pm 36.29)\end{array}$ & $\begin{array}{c}132.5 \\
( \pm 26.95)\end{array}$ & 0.812 \\
\hline $30 \mathrm{~min}$ & $\begin{array}{c}122.7 \\
( \pm 31.38)\end{array}$ & $\begin{array}{c}122.9 \\
( \pm 32.73)\end{array}$ & $\begin{array}{c}122.2 \\
( \pm 27.57)\end{array}$ & 0.999 \\
\hline $60 \mathrm{~min}$ & $\begin{array}{c}123.3 \\
( \pm 28.49)\end{array}$ & $\begin{array}{c}127.5 \\
( \pm 30.87)\end{array}$ & $\begin{array}{c}123.8 \\
( \pm 29.02)\end{array}$ & 0.941 \\
\hline
\end{tabular}

$\mathrm{PaO}_{2}$ - partial pressure of oxygen in arterial blood. SDstandard deviation. 


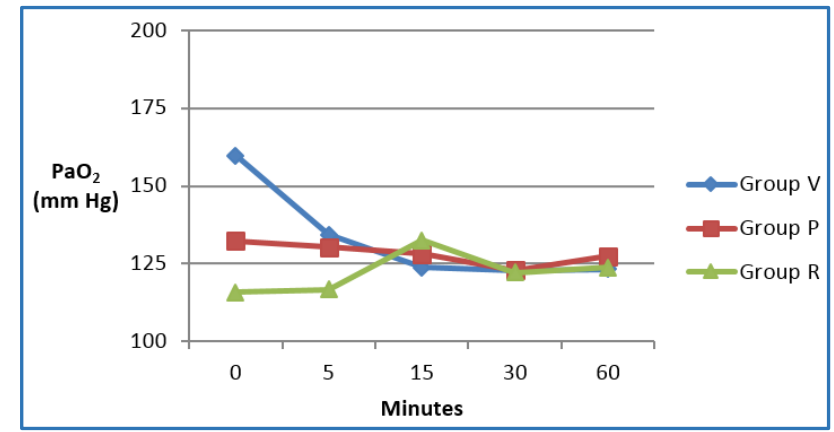

Figure 1. Intraoperative $\mathrm{PaO}_{2}$ changes in the three groups

\begin{tabular}{|c|c|c|c|c|}
\hline $\begin{array}{c}\mathrm{PaCO}_{2} \\
(\mathbf{m m} \text { Hg) }\end{array}$ & $\begin{array}{c}\text { Group V } \\
\text { Mean }( \pm \mathbf{S D})\end{array}$ & $\begin{array}{c}\text { Group P } \\
\text { Mean }( \pm \mathbf{S D})\end{array}$ & $\begin{array}{c}\text { Group R } \\
\text { Mean ( } \pm \text { SD) }\end{array}$ & p value \\
\hline Baseline & $\begin{array}{c}39.10 \\
( \pm 2.96)\end{array}$ & $\begin{array}{c}36.10 \\
( \pm 4.40)\end{array}$ & $\begin{array}{c}36.4 \\
( \pm 4.16)\end{array}$ & 0.185 \\
\hline $5 \mathrm{~min}$ & $\begin{array}{c}39.6 \\
( \pm 4.52)\end{array}$ & $\begin{array}{c}38.6 \\
( \pm 4.03)\end{array}$ & $\begin{array}{c}37.6 \\
( \pm 5.4)\end{array}$ & 0.639 \\
\hline $15 \mathrm{~min}$ & $\begin{array}{c}39.5 \\
( \pm 2.99)\end{array}$ & $\begin{array}{c}39.1 \\
( \pm 3.98)\end{array}$ & $\begin{array}{c}38.3 \\
( \pm 5.03)\end{array}$ & 0.801 \\
\hline $30 \mathrm{~min}$ & $\begin{array}{c}40.10 \\
( \pm 5.13)\end{array}$ & $\begin{array}{c}38.7 \\
( \pm 4.96)\end{array}$ & $\begin{array}{c}39.6 \\
( \pm 6)\end{array}$ & 0.842 \\
\hline $60 \mathrm{~min}$ & $\begin{array}{c}41.10 \\
( \pm 5.40)\end{array}$ & $39.6( \pm 6.27)$ & $\begin{array}{c}39.7 \\
( \pm 5.45)\end{array}$ & 0.808 \\
\hline \multicolumn{5}{|c|}{ Table 2. Intraoperative PaCO } \\
\hline
\end{tabular}

$\mathrm{PaCO}_{2}$ - partial pressure of oxygen in arterial blood

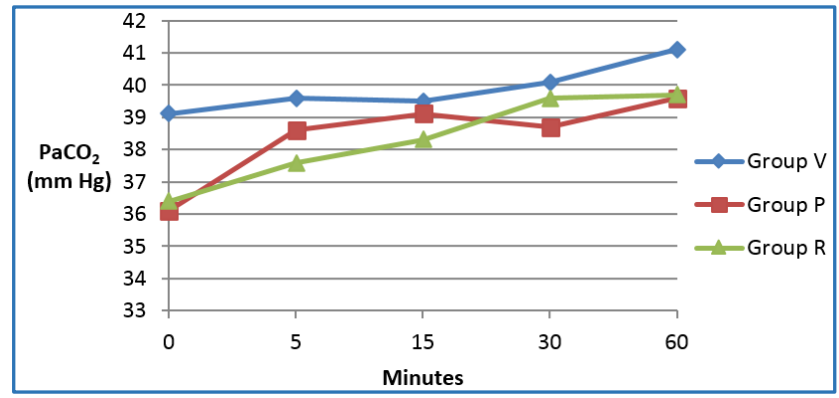

Figure 2. Intraoperative $\mathrm{PaCO}_{2}$ changes in the three groups

\section{Alveolar Recruitment}

In group $\mathrm{R}$, ten minutes after pneumoperitoneum alveolar recruitment was carried out by increasing PEEP in increments of $10,15 \mathrm{~cm} \mathrm{H}_{2} \mathrm{O}$ ( 3 breaths each) and $20 \mathrm{~cm} \mathrm{H}_{2} \mathrm{O}$ (10 breaths). Alveolar recruitment was possible in only 6 out of 10 patients, as in the remaining 4 patients $P_{\text {peak }}$ raised to more than $40 \mathrm{~cm} \mathrm{H}_{2} \mathrm{O}$. Airway pressures, $\mathrm{SpO}_{2}, \mathrm{EtCO}_{2}$ and $\mathrm{ABG}$ were recorded 5 minutes after recruitment. By repeated measures analysis followed by post hoc analysis by least square deviation method, we found that $\mathrm{PaO}_{2}$ at 5 min after recruitment [132.5 $( \pm 26.9)]$ was significantly higher than $\mathrm{PaO}_{2}$ at 5 minutes after intubation [115.8 $\left.( \pm 20.2) \mathrm{p}=0.024\right]$ and at 5 minutes after pneumoperitoneum [116.7 $( \pm 19.8)$ $\mathrm{p}=0.001] . \mathrm{PaCO}_{2}$ and $\mathrm{pH}$ at 5 minutes after recruitment was comparable with $\mathrm{PaCO}_{2}$ at specific time intervals.

There is no difference in the $\mathrm{SpO}_{2}$ among the three groups. The postoperative arterial blood gas analysis was done in all groups at 60 and 120 minutes postoperatively and they were comparable between the groups as shown in table 3 .

\begin{tabular}{|c|c|c|c|c|c|}
\hline \multicolumn{2}{|c|}{$\begin{array}{c}\text { Postoperative } \\
\text { ABG }\end{array}$} & \begin{tabular}{|c|} 
Group V \\
$($ Mean \pm SD)
\end{tabular} & $\begin{array}{c}\text { Group P } \\
(\text { Mean } \pm \text { SD) }\end{array}$ & $\begin{array}{c}\text { Group R } \\
(\text { Mean } \pm S D)\end{array}$ & $\begin{array}{c}\mathbf{p} \\
\text { value }\end{array}$ \\
\hline \multirow[t]{2}{*}{$\mathrm{pH}$} & $\begin{array}{l}\text { At } 60 \\
\min \end{array}$ & $7.36 \pm 0.02$ & $7.34 \pm 0.18$ & $7.33 \pm 0.018$ & 0.063 \\
\hline & $\begin{array}{c}\text { At } 120 \\
\min \end{array}$ & $7.35 \pm 0.03$ & $7.35 \pm 0.02$ & $7.35 \pm 0.03$ & 0.988 \\
\hline \multirow{2}{*}{$\begin{array}{c}\mathrm{PaO}_{2} \\
(\mathrm{~mm} \mathrm{Hg})\end{array}$} & $\begin{array}{l}\text { At } 60 \\
\text { min }\end{array}$ & $103.3 \pm 16.4$ & $104.6 \pm 18.8$ & $103.7 \pm 11.7$ & 0.983 \\
\hline & $\begin{array}{c}\text { At } 120 \\
\text { min }\end{array}$ & $98.3 \pm 12.4$ & $100 \pm 14.7$ & $98.1 \pm 9.9$ & 0.933 \\
\hline \multirow{2}{*}{$\begin{array}{c}\mathrm{PaCO}_{2} \\
(\mathrm{~mm} \mathrm{Hg})\end{array}$} & $\begin{array}{l}\text { At } 60 \\
\text { min }\end{array}$ & $40.8 \pm 5.1$ & $41.2 \pm 7.1$ & $41 \pm 7.2$ & 0.991 \\
\hline & $\begin{array}{c}\text { At } 120 \\
\min \end{array}$ & $40 \pm 4.5$ & $38.9 \pm 6$ & $39.3 \pm 5.7$ & 0.901 \\
\hline
\end{tabular}

\section{DISCUSSION}

According to the 1991 National Institutes of Health (NIH) consensus conference on gastrointestinal surgery for severe obesity, patients are candidates for bariatric surgery if they are morbidly obese (BMI $>40 \mathrm{~kg} / \mathrm{m}^{2}$ or $\geq 35 \mathrm{~kg} / \mathrm{m}^{2}$ with comorbidities), have failed attempts at diet and exercise, are motivated and well informed, and are free of significant psychological disease. 6 All the patients scheduled for laparoscopic bariatric surgery in our study fulfilled the above criteria.

Increasing levels of BMI is significantly associated with decreasing $\mathrm{PaO}_{2}$ and increasing $\mathrm{PaCO}_{2} .{ }^{7}$ Pneumoperitoneum and systemic resorption of $\mathrm{CO}_{2}$ associated with laparoscopic surgery may further impact oxygenation in the obese. Reduction in arterial oxygenation during anaesthesia has been seen to be greater in obese compared with lean patients and this is directly related to the increase in BMI. Morbid obesity can cause a restrictive lung syndrome with reduction in lung volumes, expiratory reserve volume and functional residual capacity (FRC) due to restricted thoracic wall movement, decreased lung compliance and increased airway resistance. These factors along with general anaesthesia may cause alveolar collapse and ventilation/perfusion mismatching leading to impaired oxygenation.

Various ventilatory strategies have been proposed to improve gas exchange during general anaesthesia in morbidly obese patients. We compared alveolar recruitment manoeuvre with the conventional modes of ventilation to find out whether alveolar recruitment has a beneficial effect on oxygenation and $\mathrm{CO}_{2}$ removal.

In several studies, alveolar recruitment during bariatric surgery has been found to be beneficial on gas exchange and respiratory mechanics and this effect is maintained on repeating the manoeuvre.8,9 There are no specific recommendations regarding recruitment manoeuvres due to high heterogeneity in the delivery methods of recruitment manoeuvres. In our study, we performed lung recruitment manoeuvre at 10 minutes after creation of pneumoperitoneum, by increasing the PEEP in a stepwise manner. Initially we increased the PEEP to $10 \mathrm{~cm} \mathrm{H}_{2} \mathrm{O}$ for 3 breaths, then to $15 \mathrm{~cm} \mathrm{H}_{2} \mathrm{O}$ for 3 breaths and finally to $20 \mathrm{~cm}$ $\mathrm{H}_{2} \mathrm{O}$ for 10 breaths. The recruitment manoeuvre done in our study was similar to the manoeuvre which was done in Whalen's study. ${ }^{8}$ However we did a single recruitment manoeuvre and studied whether the beneficial effect of recruitment if any was sustained. Talab et al demonstrated 
that alveolar recruitment manoeuvre is effective only if it is followed by PEEP adequate enough to maintain the recruited alveoli.10 Therefore in our study, after alveolar recruitment manoeuvre we maintained a PEEP of $12 \mathrm{~cm} \mathrm{H}_{2} \mathrm{O}$ to maintain the recruited alveoli. Literature shows that pressure controlled ventilation is more effective in improving oxygenation and $\mathrm{CO}_{2}$ elimination in morbidly obese individuals. ${ }^{10}$ This prompted us to include pressure controlled ventilation in our study. Also, there are limited studies comparing the efficacy of alveolar recruitment with the commonly used intraoperative ventilatory strategies such as pressure control and volume control ventilation during laparoscopic bariatric surgery.

Our study showed that, in the recruitment group, $\mathrm{PaO}_{2}$ at $5 \mathrm{~min}$ after recruitment [132.5( \pm 26.9$)]$ was significantly higher than $\mathrm{PaO}_{2}$ at 5 minutes after intubation [115.8( \pm 20.2$)$ $\mathrm{p}=0.024]$ and at 5 minutes after pneumoperitoneum $[116.7( \pm 19.8) p=0.001]$. In the postoperative period, at 60 minutes $\mathrm{PaO}_{2}$ was $103.7 \pm 11.7 \mathrm{~mm} \mathrm{Hg}$ in the recruitment group and $98.3 \pm 12.4$ at 120 minutes $(p>0.05)$. This showed that the benefit of a single recruitment manoeuvre was transient and the benefit on arterial oxygenation did not sustained during the intraoperative and postoperative period. Alveolar recruitment manoeuvre did not had any effect on $\mathrm{PaCO}_{2}$ levels in our study in contrary to the Whalen et al study, where recruitment lead to significant increase in $\mathrm{PaCO}_{2}$ levels. ${ }^{8}$

Our study results were different with the study conducted by Ahmed et al during laparoscopic bariatric surgery, in which they compared conventionally ventilated group with a group receiving alveolar recruitment with a PEEP of $40 \mathrm{~cm} \mathrm{H}_{2} \mathrm{O}$ and a third group receiving alveolar recruitment manoeuvre repeated 30 and 90 minutes after surgery with both recruitment groups receiving PEEP of $10 \mathrm{~m}$ of $\mathrm{H}_{2} \mathrm{O}$ till the end of the procedure. They found that alveolar recruitment improved gas exchange and repeated manoeuvres maintained adequate gas exchange and lead to better compliance. ${ }^{9}$ In our study, though the arterial oxygenation improved temporarily after alveolar recruitment, there was no significant difference in arterial oxygenation and $\mathrm{CO} 2$ removal in between the three groups.

Our study design was similar to that of Whalen et al. However, we compared the recruitment group with the conventional intraoperative modes such as volume controlled and pressure controlled ventilation unlike the study done by Whalen et al, in which they compared the recruitment group with only volume controlled ventilation. Whalen et al divided 20 patients into two groups; in recruitment group PEEP was increased in stepwise fashion of $10-15-20 \mathrm{~cm} \mathrm{H}_{2} \mathrm{O}$, not to exceed Ppeak of $50 \mathrm{~cm} \mathrm{H}_{2} \mathrm{O}$ and then PEEP set at $12 \mathrm{~cm} \mathrm{H}_{2} \mathrm{O}$, whereas control group received PEEP of $4 \mathrm{~cm} \mathrm{H}_{2} \mathrm{O}$. They found that recruitment group had a significantly higher intraoperative $\mathrm{PaO}_{2} / \mathrm{FiO}_{2}$ ratio and dynamic compliance compared to the control group throughout the course of operation, but it promptly dissipated after tracheal extubation. ${ }^{8}$

Previous studies stated that the rationale for the recruitment manoeuvre is based on the fact that sustained, high airway pressures are required to resolve atelectasis in experimental models. ${ }^{11}$ This beneficial effect of alveolar recruitment on atelectasis in morbidly obese individuals was demonstrated through computed tomography images. ${ }^{12}$

VCV utilizes a constant flow to deliver a target tidal volume and thus ensure satisfactory minute ventilation. ${ }^{4}$ However PCV uses a decelerating flow which reaches the highest possible value at the beginning of inspiration, while having a preset pressure limitation but minimum tidal volume. Flow diminishes throughout inspiration according to target pressure and resulting tidal volume depends on pressure limitation and chest compliance. 4 Varying observations have been made with respect to oxygenation and carbon dioxide elimination in studies comparing ventilatory modes in patients undergoing bariatric surgery. In our study, there is no significant difference $(\mathrm{p}>0.05)$ in both $\mathrm{PaO}_{2}$ and $\mathrm{PaCO}_{2}$ between the VCV and PCV groups. Thereby our study inferred that both volume control and pressure control ventilation can be utilized during laparoscopic bariatric surgery. This is in agreement with the findings of Hans et al who compared PCV and VCV in 40 obese patients scheduled for gastric bypass surgery and found that $\mathrm{PaO}_{2}$ and $\mathrm{PaCO}_{2}$ were comparable between the groups. ${ }^{13}$ Our study was in contrary to the observation made by Cadi et al, where they found that intra-operative $\mathrm{PaO}_{2}$ in $\mathrm{PCV}$ group was was significantly higher than group VCV during laparoscopic gastric binding in morbidly obese. ${ }^{10}$ Whereas in a study done by De Baerdemaeker et al during laparoscopic gastric banding, they found that though arterial oxygenation was comparable between the VCV and PCV groups, $\mathrm{CO} 2$ elimination was better with pressure controlled ventilation. ${ }^{14}$

This study has shown that though alveolar recruitment manoeuvre improves arterial oxygenation during laparoscopic bariatric surgery, there was no significant difference in $\mathrm{PaO}_{2}$ and $\mathrm{PaCO}_{2}$ when compared with both volume controlled and pressure controlled ventilation. The lack of significance may be due to the small sample size and further studies with large number of patients are required.

\section{CONCLUSION}

We found that alveolar recruitment leads to temporary improvement in oxygenation during laparoscopic sleeve gastrectomy in morbidly obese individuals and recruitment must be individualized to obtain maximum benefit. Repeated recruitment manoeuvres may be done to sustain the benefit achieved in arterial oxygenation. Our study also showed that recruitment manoeuvre did not affect the carbon dioxide elimination. Also, we inferred that, on comparing alveolar recruitment manoeuvre with the conventional pressure controlled ventilation and volume controlled ventilation, there was no significant difference in arterial oxygenation and CO2 elimination ( $p>0.05)$. Alveolar recruitment manoeuvre may be considered whenever an improvement in arterial oxygenation is required during laparoscopic bariatric surgery in morbidly obese patients.

\section{REFERENCES}

[1] Pelosi P, Croci M, Ravagnan I, et al. The effects of body mass on lung volumes, respiratory mechanics, and gas exchange during general anesthesia. Anesth Analg 1998;87(3):654-60. 
[2] Talab HF, Zabani IA, Abdelrahman HS, et al. Intraoperative ventilatory strategies for prevention of pulmonary atelectasis in obese patients undergoing laparoscopic bariatric surgery. Anesth Analg 2009;109(5):1511-6.

[3] Bardoczky GI, Yernault JC, Houben J, et al. Large tidal volume ventilation does not improve oxygenation in morbidly obese patients during anesthesia. Anesth Analg 1995;81(2):385-8.

[4] Nichols D, Haranath S. Pressure control ventilation. Crit Care Clin 2007;23(2):183-99.

[5] Pelosi P, Gama de Abreu M, Rocco PR. New and conventional strategies for lung recruitment in acute respiratory distress syndrome. Critical Care 2010;14(2):210.

[6] NIH conference. Gastrointestinal surgery for severe obesity. Consensus Development Conference Panel. Ann Intern Med 1991;115(12):956-61.

[7] Gabrielsen, Lund MB, Kongerud J, et al. The relationship between anthropometric measures, blood gases, and lung function in morbidly obese white subjects. Obes Surg 2011;21(4):485-91.

[8] Whalen FX, Gajic O, Thompson GB, et al. The effects of alveolar recruitment maneuver and positive end expiratory pressure on arterial oxygenation during laparoscopic bariatric surgery. Anesth Analg 2006;102(1):298-305.
[9] Ahmed WG, Abu-Elnasr NE, Ghoneim SH. The effects of single vs. repeated vital capacity maneuver on arterial oxygenation and compliance in obese patients presenting for laparoscopic bariatric surgery. Ain Shams J Anesthesiol 2012;5(1):121-32.

[10] Cadi P, Guenoun T, Journois D, et al. Pressurecontrolled ventilation improves oxygenation during laparoscopic obesity surgery compared with volume controlled ventilation. Br J Anesth 2008;100(5):70916.

[11] Tokics L, Hendenstierna G, Strandberg A, et al. Lung collapse and gas exchange during general anesthesia: effects of spontaneous breathing, muscle paralysis and positive end-expiratory pressure. Anesthesiology 1987;66(2):157-67.

[12] Reinius H, Jonsson L, Gustafsson S, et al. Prevention of atelectasis in morbidly obese patients during general anesthesia and paralysis: a computerized tomography study. Anesthesiology 2009;111(5):979-87.

[13] Hans G, Kaba A, Pregaldien AA, et al. Pressurecontrolled ventilation does not improve gas exchange in morbidly obese patients undergoing abdominal surgery. Obes Surg 2008;18(1):71-6

[14] De Baerdemaeker LE, Van der Herten C, Gillardin JM, et al. Comparison of volume-controlled and pressurecontrolled ventilation during laparoscopic gastric banding in morbidly obese patients. Obes Surg 2008;18(6):680-5. 